\title{
ENTREVISTA
}

\section{OS RUMOS DA PESQUISA NO CAMPO DA AUTOBIOGRAFIA SOBRE ENVELHECIMENTO}

\author{
Aurea da Silva Pereira \\ Danise Grangeiro
}

Vera Brandão possui graduação em Pedagogia pela Universidade de São Paulo (1975), mestrado em Ciências Sociais pela Pontifícia Universidade Católica de São Paulo (1998), doutorado em Ciências Sociais pela Pontifícia Universidade Católica de São Paulo (2004) e Pós-Doutorado em Gerontologia Social pela Pontifícia Universidade Católica de São Paulo (2016). Atualmente é asses. regular/efetiva do cons. científico da Pontifícia Universidade Católica de São Paulo e docente - Coordenadoria Geral de Especialização, Aperfeiçoamento e Extensão. Tem experiência na área de Antropologia, com ênfase em Produção Simbólica e Reprodução Cultural, atuando principalmente nos seguintes temas: memória social e autobiográfica, educação continuada, envelhecimento, longevidade, mídia.

\section{Aurea da Silva Pereira:}

Sabemos que há mais de uma década vem se dedicando aos estudos sobre envelhecimento no Brasil. Que balanço você faz acerca do que já tem feito e do que pode ser feito?

\section{Vera Brandão:}

Meu trabalho com idosos teve início em 1994 com o inesperado convite de uma amiga que recém assumira a coordenação de uma UNATI na cidade de São Paulo, um ano após sua implantação. Nunca tinha trabalhado com idosos, ou feito estudos sobre o tema ainda abordado de forma incipiente. As alunas queriam, segundo ela, aulas de Antropologia. Mas, o que? Ela não sabia. Propus, antes de qualquer iniciativa formal, uma conversa com o grupo. Deste encontro 'investigativo' dos saberes do grupo saiu uma proposta construída, de modo conjunto, denominado Memória e Cultura - a partir do resgate das manifestações das 'culturas' de um grupo de idosas (entre 50 a 85 anos) - receitas de família, fotos, objetos e tudo o que lembrasse a 'saga' familiar. 
Interessante ressaltar que o bairro de Santo Amaro no qual estava inserida UNATI, zona sul da cidade, teve uma ocupação multiétnica com descendentes de alemães (como primeira colônia estrangeira no Brasil, a partir de 1827, por ordem do Imperador Pedro I), italianos, espanhóis, e de imigrantes dos países de leste europeu - que vieram no período da virada do século XIX-XX, e nos períodos entre as duas grandes guerras mundiais, ou nos anos subsequentes, além dos migrantes de diferentes regiões do país (especialmente nordestinos).

Esta região, distante do centro da cidade, tornou município em1832 e foi anexado à cidade como bairro em 1935. Esta diversidade de origens e experiências das culturas de origem e destino se espelhava no grupo, que também mesclava diferentes níveis de escolaridade e condições socioeconômicas. A diversidade do grupo indica a riqueza das experiências vividas e trazidas nos relatos, que eram partilhados em rodas de conversa e, posteriormente, escritos (alguns com ajuda) e se transformavam em 'cadernos de memórias' - sendo os textos digitalizados pela secretária da Universidade e em momento especial partilhadas com todos os participantes.

Duas observações que esclarecem melhor a perspectiva teórica na qual se baseia este trabalho (realizado até o ano 2000 nesta Instituição) e seu impacto no grupo:

A) Algumas das participantes ficavam com 'medo' das rememorações e do convite à escrita posterior, e diziam: 'sofri muito, não quero lembrar'; 'minha história não tem graça, não aconteceu nada'; 'mas, para quem interessa a minha história?'. Ou 'perdi a prática de escrever, faço muitos erros'; 'estudei pouco tempo... tenho dificuldade'; 'Escrever?!, Acho que não consigo...' Mas, estimulados por colegas que tinham entusiasmo e interesse pelo trabalho, acabavam participando com apoio, mas sem interferência direta, da minha parte - deixava o trabalho 'fluir' e percebi o desenvolvimento de uma solidariedade grupal, seja nas partilhas orais ou no processo de escrita. Outro resultado importante foi o impacto nas famílias filhos e netos - que recebiam com interesse o projeto, e mesmo os que não deram muita atenção depois ficaram surpresos com os resultados observados nos 'donos da história - “Mãe, como você deve ter sofrido, eu não sabia [...]” ou “[...] Vó, mas você fugiu de casa para casar? naquele tempo!”.

Ao final, mesmo as mais resistentes, diziam: '- percebi que minha vida teve bons momentos, não só ruins'; -'eu sofri, mas contando a minha 
história fiquei feliz de ver aonde cheguei, e o que consegui'; '- foi duro, mas deu tudo certo, no final'; 'passei a vida a limpo'. Afirmações como estas indicavam um processo de 'reapropriação' da trajetória e um 'orgulho' da identidade reconstruída. Essa atividade passou a ser denominado por elas de 'Oficina da Memória’.

Este trabalho teve continuidade em outros espaços com idosos, e a partir do ano 2000 passamos a oferecer pelo NEPE, no módulo extensão, a Oficina Memória Autobiográfica - Teoria e Prática, dirigida a profissionais da área do envelhecimento, que se tornaram multiplicadores desta metodologia, com inúmeros trabalhos relevantes na cidade de São Paulo e outras cidades e estados. Este trabalho de formação continuada foi também realizado em outros Estados sempre com ótimos resultados.

O interesse na continuação no estudo pelo grupo inicial foi impulso para a formação do Grupo de Estudos da Memória - GEM, alocado no NEPEPUC-SP, com pesquisas teórico-práticas, envolvendo ações junto ao público idoso, que resultaram em muitos trabalhados, apresentados em Congressos e publicados. O grupo permaneceu atuante ate o final de 2016 quando encerrou suas atividades por questões internas à Universidade.

B) a metodologia foi sendo construída e aprimorada ao longo do tempo, pois além da bagagem teórica da área da Sociologia e Antropologia Cultural, e da 'escuta' em primeira mão' dos trabalhos de campo, advinda da primeira formação em Ciências Sociais, a formação pedagógica da segunda graduação em Educação (cursos realizados na USP) forneceu as bases para a prática. Importante também, neste início, as reflexões teóricas sobre as memórias trazidas pelas sensações, decorrentes de curso em Literatura e Artes realizado na Aliança Francesa, sobre a obra de Marcel Proust. Nela, ficava claro o movimento constante de fluxo e refluxo da memória pessoal e grupal, trazendo a imagem de fatos vividos outrora, de pessoas e lugares compartilhados com diferentes grupos, que vimos surgir entre as idosas que recuperavam a história viva, atualizada e reinserida no contexto atual.

No momento do aceite do primeiro grupo para realizar esta atividade iniciei a busca por conhecimentos na área incipiente do envelhecimento - fortemente marcado pelo estigma da doença - de início de forma aleatória e, posteriormente, de forma sistemática a partir do convite para participar com pesquisadora do "Núcleo de Estudo e Pesquisa do 
Envelhecimento" da PUC-SP, que gestava o curso de Pós-graduação em Gerontologia, implantado em 1997, do qual faço parte até hoje.

O primeiro contato com a metodologia do movimento da 'pesquisa (auto)biográfica' foi a leitura, no ano 2000, do trabalho de Marie-Christine Josso - Cheminer vers soi (1991). A partir de então passei a ler todo o material que encontrava nesta linha, o que possibilitou refinar o trabalho com bases teóricas mais amplas, até a participação no II Congresso Internacional de Pesquisa (Auto) Biográfica (Salvador, 2006) com a apresentação de um pôster, ponto de virada nos meus estudos e práticas, seguida da aproximação pessoal, no III Congresso (Natal, 2008), com Kátia Mota e Aurea Pereira (UNEB), quando participamos da mesma sessão de Comunicação - parceria/amizade que se consolidou com o tempo.

Abaixo insiro parte de texto sistematizado sobre o impacto da aproximação com o grupo de pesquisa (auto)biográfico em texto apresentado e publicado nos Anais do VII CIPA (Cuiabá, 2016) ${ }^{1}$ no qual apresento o Memorial Acadêmico elaborado no estágio pós-doutoral em Gerontologia Social - PUC/SP (2014-2015):

A escrita autobiográfica se apresentou [...] como caminho natural na senda aberta desde nosso primeiro projeto Memória e Cultura, realizado junto à população idosa, e um dos pontos de inflexão profissional, como explicitado adiante.

Ressaltamos que o aprofundamento das reflexões a respeito da formação e pesquisa (auto) biográfica deu-se a partir das leituras iniciais de Josso $(1999 ; 2006)$ e Momberger-Delory (2006; 2008; 2012), que forneceram novas bases teóricas ao trabalho com memória social que realizávamos na perspectiva antropológica - que busca ouvir os "narradores de primeira mão" (GEERTZ, 1989) - a respeito das construções sociais, bases de suas identificações como sujeitos da cultura - realizado com grupos de idosos, desde o ano 1994, e na formação profissional continuada com profissionais, desde o ano 2000.

Segundo Josso (1999, p. 14), suas reflexões sobre "história de vida em formação" indicam que essa abordagem abre

\footnotetext{
${ }^{1}$ Brandão, V. (2016). Anais do VII Congresso Internacional de Pesquisa (Auto)Biográfica UFMT - Cuiabá ISSN 2178-0676. http://viicipa.com.br/wordpress/wp-content/uploads/2016/08/C2T_O-MEMORIALACADE\%CC\%82MICO-EM-FORMAC\%CC\%A7A\%CC\%830-CONTINUADA.pdf
} 
“novo horizonte teórico no campo da educação de adultos para uma abordagem da formação centrada sobre o sujeito aprendiz, utilizando a mediação de uma metodologia de pesquisa-formação articuladas às histórias de vida".

As participações nos Congressos Internacionais de Pesquisa (Auto) Biográfica, a partir de 2006, o contato com os pesquisadores e autores da área e a vasta bibliografia que se materializava a cada encontro, ampliaram e despertaram crescente interesse nos estudos sobre o tema do Memorial como gênero acadêmico autobiográfico, apoiado especialmente em Passeggi (2000, 2006 a/b; 2008; 2013), autora guia do trabalho aqui apresentado.

Os estudos do envelhecimento na perspectiva de Gerontologia Social - que foca não só a doença, mas o sujeito em seu processo de vida - se mantém desde o início de nosso trabalho até hoje. Acredito que foi a originalidade na abordagem e a experiência cotidiana com os idosos o motivo do convite, no início da trajetória, para participar do NEPE.

Ao longo dos anos os estudos e pesquisas, além da prática com idosos e a formação continuada a profissionais, de diferentes áreas de atuação, que buscam aprimoramento na área envolvendo o processo de envelhecimento e as perspectivas atuais da longevidade avançada ${ }^{2}$, foram se articulando com o tema da metodologia (auto)biográfica e, neste sentido, a força do resgate das trajetórias, que observamos nos idosos, e mostrou-se (trans)formadora também para os profissionais (a partir do ano 2000). Este caminho tem se mostrado desafiador, autoformador e transformador e nele seguimos, pois somos testemunhas do seu impacto para os idosos e, a partir daí, na formação continuada de profissionais.

\section{Danise Grangeiro:}

Temos acompanhado as publicações do Portal de Envelhecimento da PUC-SP e sabemos que tem uma rede de colaboradores. Sabemos também que você é uma das responsáveis pelo Portal. Qual tem sido o impacto das

\footnotetext{
${ }^{2}$ Côrte, B; Brandão, V. (2018). Longevidade Avançada - A reinvenção do tempo. Revista Kairós Gerontologia, 21(1), 213-241. ISSNe 2176-901X. São Paulo (SP), Brasil: FACHS/NEPE/PEPGG/PUC-SP https://revistas.pucsp. br/index.php/kairos/article/download/39523/26782
} 
publicações para a rede de pesquisadores de envelhecimento, sobretudo para a sociedade, para nós que envelhecemos todos os dias?

\section{Vera Brandão:}

Implantado em 2004, o espaço midiático Portal do Envelhecimento ${ }^{3}$, idealizado por nossa colega jornalista Dra. Beltrina Côrte, representa um meio de comunicação democrático, cujo objetivo é a construção de uma rede de solidariedade entre diferentes segmentos sociais, além de pensar nova concepção sobre a velhice em sua complexidade e múltiplas dimensões.

No ano de 2005, o Portal do Envelhecimento foi considerado como

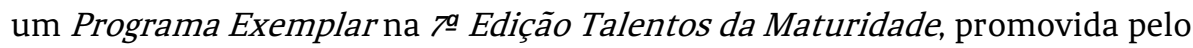
Banco Real, reconhecimento que deu importante impulso nesse início de trajetória.

Em agosto 2010, como parte de sua natural expansão, implantou-se a Revista Portal de Divulgação, da qual sou editora, cujos artigos relacionados à velhice, envelhecimento e longevidade humana, são abordados com rigor, simplicidade e acessíveis ao leitor não especialista. A partir da edição de no 39 , publicada em 2013, a Revista, mensal até então, passou a ser atualizada trimestralmente.

Nessa perspectiva, o Portal do Envelhecimento oferece acesso livre e imediato ao seu conteúdo, seguindo o princípio de disponibilizar gratuitamente o conhecimento sobre o envelhecimento ao público amplo, proporcionando, além de sua maior democratização, a consolidação da cultura da longevidade - com a transferência de informações qualificadas sobre a velhice e o envelhecimento, possibilitando o acesso democrático ao conhecimento. Missão social que tem norteado a produção de conteúdos de credibilidade, tornando-se hoje referência sobre o Longeviver no país.

A linha editorial do Portal do Envelhecimento adota os conceitos da Gerontologia Social, cuja perspectiva consiste em mostrar que a vida está acima da doença; que em um corpo doente habita um sujeito; um ser que envelhece e não unicamente um ser que adoece. Apoiados em Martín-Barbero (2014, p. 18) ${ }^{4}$, consideramos o meio virtual como um espaço democrático de

${ }^{3} \mathrm{https://www.portaldoenvelhecimento.com.br/}$

${ }^{4}$ Martín-Barbero, J. (2014). A Comunicação na educação. São Paulo: Contexto. 
comunicação e educação continuada, pela palavra mediadora e geradora de "novos sentidos que possam reinventar o presente e reconstruir o futuro".

A reinvenção do presente e a reconstrução do futuro compõem o eixo principal desse desafio no panorama da crescente longevidade humana. Contexto no qual consideramos a comunicação virtual como meio de informação, formação e espaço para a palavra dos idosos e profissionais da área. Notamos ser grande o desconhecimento a respeito do processo de envelhecimento e longevidade, mesmo que hoje seja tema da grande mídia.

Nela surgem questões eivadas, muitas vezes, de prejulgamentos e estigmas, o que em nada colabora para que esse período da vida, parte do ciclo vital, seja compreendido em suas reais dimensões. Seria ambicioso pensar esse espaço virtual como campo de possibilidade para o diálogo social amplo e transformador? Voltamos a Martín-Barbero

(2014, p. 33) que afirma:

Dialogar é arriscar uma palavra ao encontro não de uma ressonância, de um eco de si mesma, mas sim de outra palavra, da resposta de um outro [...] é descobrir na trama de nosso próprio ser a presença dos laços sociais que nos sustentam. É lançar as bases para uma posse coletiva, comunitária, do mundo.

Os muitos leitores do site, espalhados do Brasil e países lusófonos, atestam que essa não é uma ambição qualquer, e indicam a necessidade e pertinência do espaço de cidadania e solidariedade, proposta do Portal do Envelhecimento, em seus 15 anos online, e com a implantação da Revista Portal de Divulgação (2010-2017) que a partir de janeiro de 2019 foi renomeada de Revista Longeviver ${ }^{5}$, seguindo os mesmos critérios anteriores.

Notamos que as publicações do Portal do Envelhecimento atualizado diariamente, e os artigos publicados trimestralmente na Revista, impactam o público em geral, em especial idosos e familiares, e surgem como ponto de referência para práticas profissionais, conforme referências em artigos recebidos para avaliação, e em inúmeros trabalhos acadêmicos. Ainda neste ano de 2019 foi apresentada tese de doutorado que tinha como um dos

${ }^{5}$ https://revistalongeviver.com.br/index.php/revistaportal 
destaques de análise o conteúdo do Portal do Envelhecimento ${ }^{6}$. Neste trabalho a autora indica que o site contava em 2018 com 44576 seguidores.

Ressaltamos que a Revista, no contexto específico, persegue outro importante objetivo - ser meio de educação continuada não formal, na medida em que se engaja na perspectiva atual de abertura de novos espaços de construção de conhecimentos, comunicação e diálogo por meio virtual. Neste contexto destaca-se a possibilidade aberta a trabalhos produzidos na graduação, tccs, relatos de experiências e reflexões como incentivo as primeiras escritas formais. Em uma mesma edição estabelece-se um diálogo formador entre trabalhos iniciais com outros escritos científicos convencionais, ampliando a troca de saberes e experiências, em muitos dos quais podemos escutar a 'voz do idoso' ao falar de seu próprio processo de envelhecimento e suas questões.

A publicação de Revista, com características abertas ao diálogo interdisciplinar e veiculada eletronicamente, insere-se na realidade imperativa da sociedade atual. Os meios digitais oferecem a ambiguidade de ter, por um lado, uma tecnologia que inventa/ cria novos modos de relacionamentos, nos quais a corporeidade não se faz presente, afastando-se do princípio do gesto, como primeiro grau de comunicação (Martín-Barbero, 2014, p. 80) e, por outro, instrumentaliza a população para um conhecimento gerador de novas possibilidades de viver e envelhecer, divulgando também inúmeras novidades tecnológicas que colaboram na manutenção da independência dos idosos, e certo conforto aos familiares ${ }^{7}$. Afirma o mesmo autor que "as transformações no modo como circula o saber constitua uma das mais profundas transformações que uma sociedade pode sofrer".

Refletindo sobre nosso percurso consideramos que no exercício de seleção de conteúdos para publicação nas páginas do Portal do Envelhecimento e na Revista realizamos uma curadoria de saberes de amplo

\footnotetext{
${ }^{6}$ Liesenberger, C. (2019). Sob o signo do tempo: velhice e envelhecimento em perfis de idosos nas mídias. Tese de Doutorado. Escola de Comunicação e Artes - USP. Área - Teoria, Pesquisa e Comunicação.http://www.teses.usp. br/teses/disponiveis/27/27152/tde-16052019-165919/pt-br.php 7 Tecnologia ajuda idosos a permanecerem mais tempo em suas casas. http://www.portaldoenvelhecimento.com/tecnologias/item/3631-tecnologia-ajuda-idosos-apermanecerem-mais-tempo-em-suas-casas (maio 2015).
} 
espectro $^{8}$, seguindo o princípio de que disponibilizar gratuitamente o conhecimento sobre o processo de envelhecimento ao público proporciona, além de sua maior democratização, a consolidação da cultura do longeviver, e a formação continuada de seus leitores - idosos, famílias e profissionais. A criteriosa curadoria de conteúdos se pauta na pertinência, relevância e veracidade de informações, aquelas replicadas, sempre com citação da fonte, ou nos materiais originais enviados por uma grande rede de colaboradores, validado por seus numerosos leitores, com indica o trabalho de doutorado acima referido.

\section{Aurea da Silva Pereira:}

Nas suas publicações de livros e artigos, temos observado que tem se apropriado do método autobiográfico, da metodologia da história oral e das discussões teóricas sobre memória para escrever teoricamente sobre memória e envelhecimento. Como avalia os resultados deste trabalho e como tem contribuído para novos estudos?

\section{Vera Brandão:}

Como já indicado na pergunta 1 o caminho de construção do aporte teórico e metodológicos do nosso trabalho foi sendo construindo ao longo da constante inter-relação entre teoria e prática na perspectiva interdisciplinar, marca dos nossos trabalhos, tanto os que antecederam nossa aproximação do campo gerontológico, como os que surgem com a participação no Núcleo de Estudo e Pesquisa do Envelhecimento - NEPE, que gestava o Programa Pósgraduado em Gerontologia, de cunho Interdisciplinar.

A partir do ano 2000, a convite da professora Ivani Fazenda, passo a compor o Grupo de Estudos e Pesquisas Interdisciplinares - GEPI, do Programa de Estudos Pós-Graduados em Educação-Currículo/PUC-SP, o que torna mais clara essa perspectiva e subsidia a articulação e construção de saberes múltiplos derivados das áreas da áreas das ciências humanas, bem como os saberes informais advindos de diferentes modos de ser, viver e

\footnotetext{
${ }^{8}$ Brandão, V; Côrte, B. (2019). A Cultura do Longeviver e a Curadoria do Saber. In Barroso, A. S.; Hoyos, A.; Salmazo-Silva, H.; Fortunato, I. (org.) Diálogos Interdisciplinares do Envelhecimento. São Paulo: Edições Hipótese, pp. 91-100. https://nutecca.webnode.com/edicoes-hipotese-e-books/link direto: https://goo.gl/LDftS5.
} 
trabalhar. Na construção do conhecimento devemos ter sempre como ponto de referência o outro, nosso interlocutor no momento, lembrando que todos tem o que ensinar e todos têm o que aprender a qualquer idade.

Assim, a articulação é constante e envolve todo o percurso de formação, que na minha perspectiva, nunca termina. Na base está a experiência de vida pessoal em processo - pois vivo e aprendo a viver diariamente, e minha formação humanística da qual ressalto a Filosofia e a História - como pano de fundo aos relatos orais ou escritos das Histórias de Vida - a Antropologia como conhecimento do humano em seus saberesfazeres, apreendidos e narrados, a Educação como movimento de interlocução entre todos, na busca do bem comum, base também ancorada na Sociologia que indica a fundamental necessidade do conhecimento da realidade social do 'chão' que no qual pisamos como indivíduo e profissionais.

A aproximação da área da pesquisa (auto) biográfica veio somar, na medida mesma desta aproximação entes seres e saberes, que busco como foco de vida-trabalho, que não se separam. Lembro que o início do meu trabalho no Portal do Envelhecimento abriu inesperados caminhos para áreas 'novas' da Comunicação, Linguagens, Tecnologias e Mídias - as múltiplas linguagens e métodos próprios, e neste percurso chego a escrever meu trabalho final no estágio pós-doutoral, já referido, articulando os temas Longevidade, Educação Continuada e Mídias (2014-2015), e que tem como marca o modelo de escrita de um Memorial Acadêmico, cuja autora de referência e a prof a Maria Conceição Passeggi. Considero este um trabalho importante em um momento em que, já idosa, pude 'mergulhar' no que penso que sei e sou, e me deu coragem para desvelar uma parte da 'saga familiar' até então calada, como no trabalho apresentado no VIII CIPA - São Paulo, 2017.

Assim, é com as bases teóricas e metodológicas construídas no percurso de vida que, entrelaçando docência, pesquisa e extensão, buscamos avançar sempre descobrindo novas possibilidades de inter-relação dos saberes teóricos e as práticas de pesquisa e docência que fazem parte do meu cotidiano.

\footnotetext{
${ }^{9}$ Brandão, V. (2018). Vozes do Passado - Desvelamento, Reconfiguração, Empoderamento. VIII Congresso Internacional de Pesquisa (Auto)biográfica UNICID - São Paulo - Anais Digital BIOgraph, 2018.ISSN 21780676. CDD: 920.00149. https://viiicipa.biograph.org.br/anais/
} 
Como exemplo recente deste constante aprender, cito o convite da profo Aurea Pereira a participar II Simpósio de Letramento, Identidade e Formação de Educadores, no tema: Pesquisa e Formação: percursos de uma práxis pedagógica, que considerei um desafio. O que teria a falar sobre o tema? Pensando, descobri! E apresentei o tema Cine Debate - Espaço (auto) biográfico de formação e pesquisa - Identidade, Memória e Cultura, evento realizado na UNEB- Campus II, em setembro de 2018.

Pude refletir sobre a articulação dos temas - letramento, identidade e formação - na apresentação de um projeto de educação continuada e pesquisa participativa, que teve como base o cine-debate dirigido a idosos ${ }^{10}$, experiência vivida nos anos iniciais e, posteriormente, como projeto de pesquisa acadêmica com profissionais da área gerontologica (NEPEGEM/PUC-SP, 2012-2015), trouxe para o Simpósio, acima referido, o cinedebate como potencial evento de letramento - uma prática comunicativa, um espaço de fala, como indica o texto de apoio elaborado para o evento, abaixo destacado.

Consideramos que o filme apresenta um universo rico de possibilidades por meio de múltiplas linguagens: o roteiro escrito; a música (e outros sons); as cores e seus significados; os silêncios expressivos; as metáforas, estimulando a criação de um universo 'paralelo' no qual 'mergulhamos' - um tempo fora do tempo - como formas não verbais de comunicação - imagens, palavras, sentimentos/ significados, emoções.

O cine-debate pode promover, por meio das múltiplas leituras, a expressão de emoções em palavras geradoras alegria, tristeza, saudades, medo, angústia - ligadas as experiências vividas por cada um, em espaço social, relacional.

Consideramos que é na e pela palavra que nos constituímos como seres humanos. Falamos, escutamos e escrevemos a partir dessa unidade básica, baseados em uma identidade que se funda, entre outros aspectos, em uma fronteira geográfica e numa língua comum,

\footnotetext{
${ }^{10}$ Brandão, V; Côrte, B. Memória Social Autobiográfica e Cinema. Apresentado VI Congresso Iberoamericano de Psicogerontologia 2015 "Conectando la ciencia com la sabiduría de nuestros viejos pueblos". 20 a 31 Octubre La Paz, Bolivia.

O trabalho foi publicado, posteriormente, com o título Cinema e memória: recursos de aprendizagem ao longo da vida. IN Fonseca, S.C (Org.). O Envelhecimento Ativo e seus Fundamentos. São Paulo: Portal Edições, 2016.
} 
estabelecendo relações por meio de uma linguagem, que se forma na partilha de sentimentos e pensamentos. As palavras organizadas - a linguagem - tornam-se signos de comunicação, transmissão e preservação de conhecimentos, sentimentos e experiências de um passado vivido, individual e coletivamente, e reconstruído no presente. O tempo da narrativa não é o passado, mas o presente do qual parte o apelo à memória. É o ato da fala como produto de uma interação, que se mostra e materializa no contexto semiótico-ideológico, de uma determinada comunidade lingüística, que constrói o sentido das palavras, seus ecos, ressonâncias - no outro e em mim - no registro da escuta sensível.

Afirma o neurobiólogo chileno Humberto Maturana $(2004)^{11}$, pesquisador e autor de obras fundamentais para o entendimento do humano e da cultura, que a existência humana acontece no espaço relacional do conversar, e considera a linguagem um fenômeno biológico relacional, resultado da convivência e da interação entre Eu e Outro, como uma trama tecida entre conversar e emocionar denominada por ele "linguajear". Segundo ele, nossa constituição como seres humanos se concretiza nas relações mediadas pelo diálogo, no conversar, e nas redes de conversações que se estabelecem como um longo processo, construindo assim a cultura.

Assim, seguimos atentos aos novos desafios que o trabalho cotidiano com idosos que nos oferece múltiplas possibilidades de conhecimento e atuação.

Considerando que o envelhecimento faz parte da vida e os índices que indicam o acelerado envelhecimento populacional para idades superiores a 90+, podemos afirmar que são esses desafios cotidianos na área, que trazem sempre novas questões, que consideramos os campos de estudos, pesquisa e formação abertos para avanço contínuo, visando aprimorar a prática e ampliar o olhar ao panorama sobre este tempo longo de vida - o longeviver muito além do imaginado há cerca de 30 anos, quando iniciamos nossa jornada na área. Assim, continuamos a estudar, pesquisar, publicar e a realizar a curadoria de conteúdos que sejam pertinentes a este 'novo' mundo que envelhece.

\footnotetext{
${ }^{11}$ Maturana, H. e Verden-Zoeller, G. (2004). Amar e Brincar. São Paulo: Palas Athena.
} 


\section{Danise Grangeiro:}

Como o estudo da pesquisa autobiográfica sobre memória e envelhecimento tem oportunizado a pensar nas narrativas de idosos e idosos como dispositivos de aprendizagem de si?

Podemos afirmar, a partir desta longa experiência na área, que todo o trabalho autobiográfico é formador. Como já abordado, seja com idosos ou com profissionais as narrativas são, sem dúvida, dispositivos de aprendizagem pessoal. Temos longa experiência direta com idosos, de condições educacionais e socioeconômicas diversas, em diferentes lugares, ou acompanhando as pesquisas realizadas pela equipe do GEM, entre as quais a experiência do cine-debate como meio de resgate das memórias, conforme já abordado.

\section{Vera Brandão:}

Nos processos de formação continuada dos profissionais, por meio das Oficinas Autobiográficas, a redefinição identitária pessoal e profissional, e a reapropriação e reconhecimento de si, deles decorrentes, foram sempre experiências marcantes. Salientamos que as Oficinas de formação dirigidas aos profissionais foram realizadas em diferentes cidades, em outros estados do país, e em cada espaço tivemos experiências enriquecedoras e exitosas, marcadas pela força dos saberes-fazeres das culturas locais, impossíveis de relatar neste espaço ${ }^{12}$.

\section{Aurea da Silva Pereira:}

Sabe-se que no Brasil, apesar dos avanços nos estudos sobre envelhecimento, observamos que ainda há muito para avançarmos. Como avalia os novos desafios para estudos que possam de algum modo impactar a sociedade?

\footnotetext{
${ }_{12}$ Para algum detalhamento ver Côrte, B; Brandão, V. (2017). Ecos do envelhecimento na mídia - espaços da memória. Mais 60- Estudos sobre Envelhecimento. Volume 28 | Número 68, pp. 28-41. https://www.sescsp. org.br/online/artigo/11656.
} 


\section{Vera Brandão:}

Como já anunciado na resposta 3 o panorama do envelhecimento acelerado da população, especialmente no Brasil, é fenômeno que também impacta toda a América Latina e traz alertas importantes: o empobrecimento de todo continente e as consequências para áreas prioritárias à manutenção da saúde e segurança - falta de investimentos no saneamento básico, habitação, saúde e educação, com impacto direto nas políticas públicas de assistência às populações mais carentes, de todas as idades, aliado ao impacto dos fluxos migratório e imigratórios, e a completa falta de horizontes para os jovens - levando a marginalização social e todo seu elenco de descaminhos tornando o futuro assustador.

Um ponto relevante na consideração das possibilidades de viver muito com qualidade de vida deve ser a projeção que fazem as pesquisas sobre os "anos de vida saudável", ou seja, o número de anos que uma pessoa pode esperar viver sem sofrer de incapacidades; e a "carga de doenças", também fundamental na elaboração de políticas a este segmento etário. Neste cenário um ponto estratégico, para pensar o futuro da saúde de modo geral, é a redefinição de prioridades na área, e devemos estar alertas para o aumento dos quadros de demência - que duplicaram entre 1990 até 2016 - e que já é considerado no Brasil um problema de saúde pública.

Essa constatação deve ser um impulso ao planejamento estratégico, em termos econômicos e sociais, considerando também as diferenças regionais, e nelas as especifidades de cada grupo e de cada indivíduo, em sua individualidade e subjetivade.

Os estudos, pesquisas e experiências práticas, nacionais e internacionais, devem ser analisados e articulados em atualidade, pertinência e validade, visando um conhecimento amplo de uma realidade nunca vivida a longevidade avançada - na aposta de números crescente de nonagenários e centenários. Um período que simultaneamente amendronta e estimula - um desafio que não é novidade para a espécie humana no seu caminho evolutivo.

Muitos são os desafios e vamos aprendendo envelhecer, envelhecendo. O trabalho é para todos - cidadãos e profissionais - que devem experimentar novos modos de viver e longeviver no processo próprio a cada indivíduo vivendo em sociedade. Um momento impar na caminhada do homem, com suas questões universais - De onde vim? Para onde vou? Quem sou? 


\section{Danise Grangeiro:}

"Necessitamos de uma linguagem para a experiência, para poder elaborar (com outros) o sentido ou a falta de sentido de nossa experiência" afirma Larrosa (2015). Como as narrativas autobiográficas podem dar sentido a nossa falta de sentido de nossa experiência?

\section{Vera Brandão:}

Acredito que, de certo modo, já dei 'pistas' no final da resposta 5. A perspectiva dialógica do trabalho que venho realizando seja nas oficinas autobiográficas com idosos, seja na metodologia de formação é um caminho valioso.

Conviver é sempre um grande desafio! E o (con) viver entre iguais, como humanos, diferentes, por características e escolhas pessoais, na desigualdade imposta pelo 'lugar' que se vive, por escolha ou destino, acrescido do longeviver nos cenários diversos /desiguais que a contemporaneidade nos apresenta.

Na área da gerontologia social a educação continuada contempla o exercício de reaprender e refazer, individual e coletivo, se concretiza no movimento da escuta sensível nos grupos - descobrir, construir, aprender e ensinar com e a partir da intersubjetividade que se estabelece pela reflexão, trocas de experiências, análises de casos, entre outras possibilidades que surgem de encontros integrativos. Os projetos de trocas de "saberes-fazeres" são caminhos de descobertas para profissionais e formadores, e as perguntas geradoras de reflexões devem ser lançadas a todos, perspectiva que implica diálogo, parceria e interação de intersubjetividades, desafio que exige clareza dos objetivos, tempo de encontro e reflexão na busca de ações integrativas, significativas e humanizadas ${ }^{13}$.

Voltamos a citar Martin-Barbero (2014, p. 33) que afirma que dialogar é arriscar uma palavra ao encontro de outra palavra, da resposta do outro, uma ponte para a vida comunitária. Assim, é pela linguagem-palavra

\footnotetext{
${ }^{13}$ Brandão, V; Côrte, B; Fazenda, I. (2015). A Interdisciplinaridade na Gerontologia Social. Revista Interdisciplinaridade, no7, pp. 61-70. ISSN 2179-0094.

https://revistas.pucsp. br/index.php/interdisciplinaridade/article/view/25067 .
} 
que nos desvelamos em nossa humanidade e podemos construir 'novos' mundos, espaços nos quais as narrativas autobiográficas surgem como possibilidade de diálogo integrativo de sabres-fazeres, articuladas com aprofundamento dos estudos e pesquisas em espaços de trocas, este é o sentido que sempre buscamos e conseguimos alcançar ao longo desta trajetória de vida trabalho.

$\mathrm{O}$ trecho que segue em destaque, extraído do Memorial Acadêmico (já referido), apresenta a análise documental e de conteúdo, referente ao material pesquisado sobre minha produção acadêmica, e complementa, acredito eu, esta resposta. As referências bibliográficas deste trecho encontram-se no documento publicado, e já indicado na resposta 1.

A análise documental sobre o acervo buscou mapear o campo da gerontologia social e sua articulação com antropologia urbana, área de concentração da autora, e as tendências que apontam, lembrando que a comunicação dos resultados dos trabalhos de pesquisas, tanto à comunidade científica quanto à sociedade, seguindo a normatização proposta e com a qualidade esperada, estabelece "critérios de avaliação e produtividade dos indivíduos e instituições, e de áreas e subáreas de conhecimento, meio fundamental no aprimoramento e disseminação de saberem constituídos abrindo, assim, caminhos para novas reflexões e garantido também a memória da ciência" (SEVERINO, 1996, p. 165).

Nessa análise foi seguido o objetivo proposto por Bardin (2002) de apresentar a condensação de informações para armazenagem e consulta, procedimento no qual se buscou a pertinência dos resultados alcançados, suas eventuais fragilidades e, especialmente, as tendências que apontavam na abertura de novos campos de estudo e formas de compreender as realidades, a partir de pesquisas já desenvolvidas e publicadas (SÁ-SILVA; ALMEIDA; GUINDANI, 2009).

A busca realizada revelou os temas prevalentes nas produções, nas quais se destacam os temas interligados: memória; memória social; memória, identidade e cultura; tempo; e seus correlatos: história oral; narrativa autobiográfica; oficinas narrativas; ateliês autobiográficos; escritas de si; silêncios, não ditos e segredos - que se entrelaçam com envelhecimento; memória e cidadania; projetos; aprendizagem ao longo da vida; educação continuada; interdisciplinaridade; práticas de formação; construção de saberes, e problemas existências inerentes à saúde, espiritualidade e finitude. 
Nessa revisita ao acervo salientamos que alguns dos temas correlatos são naturalmente decorrentes dos prevalentes, e outros surgiram com a ampliação e aprofundamento dos estudos, pesquisas e da práxis docente, pois da convivência cotidiana com idosos e profissionais em formação a dinâmica estabelecida foi geradora de questionamentos que nos levaram a esses avanços.

Fica evidente também que os temas correlatos na área de formação se destacam, evidenciando que a busca das raízes culturais identitárias, baseada na vida vivida, nas histórias das comunidades, em seus saberes-fazeres, trazida pela memória nas práticas narrativas autobiográficas, mostram-se como possibilidades de um conhecimento de si, do grupo de pertencimento e de sua cultura.

Eles propiciam a reflexão, o encontro, e nele pela palavra, um espaço de diálogo que instrumentaliza os participantes na busca de sentidos e significados, ações integrativas para si e o grupo fortalecendo o protagonismo dos envolvidos, valorizando-os como construtores de suas vidas e histórias. No contexto desses outros modos de "conhecimento de si" a escrita autobiográfica surge também como possibilidade de (auto) formação e educação continuada (Brandão, 2008, p. 77).

\section{Aurea da Silva Pereira:}

Objetos de estudo e obras que poderiam contribuir na ampliação dos estudos do envelhecimento

\section{Vera Brandão:}

Concluindo podemos considerar que o estudo sobre o processo de vida é inesgotável porque as mudanças são constantes em todas as áreas do saber. Ao considerar a vida como processo - do nascimento à morte - em sua dinâmica social de movimento-incerteza, com o impacto do constante avanço técnico e científico, em todos os níveis, podemos dizer aos que se iniciam no tema do estudo e pesquisa do processo do envelhecimento humano que as possibilidades são inúmeras. Nunca a vida foi tão longa e, portanto, não temos experiências consolidadas deste fenômeno nunca vivido. Tudo está em construção. 
Estamos imersos no processo, o que é uma oportunidade para a abertura de novos caminhos dos saberes - necessariamente guiado pela interdisciplinaridade - e um desafio de experimentação constante. Assim, todos os temas são possíveis e promissores ao estudo e pesquisa, sempre dependendo de seu ponto de partida - ciências médicas ou humanas. Mas, como já dito, acreditamos que só a articulação de saberes, em todas as áreas, possa nos aproximar do 'desconhecido' do ser no LongeViver. A subjetividade e singularidade de vida e experiências não podem ser descartadas em nome de uma ciência 'pura', e que se propõe a ter como 'objeto' o outro. Como estudar e pesquisar a vida e seus desafios se deles me afastar?

Mesmo com muitos anos de estudo, pesquisa, docência e práticas com diferentes públicos e espaços, não posso dizer - 'estou pronta' ou 'terminei'. Todos os dias novas experiências, leio e aprendo sobre outros temas, e confirmo o celebre aforismo 'sei que nada sei'.

Um dos desafios da docência hoje é indicar uma bibliografia 'básica', porque os conceitos são dinâmicos como a própria vida, e logo são ultrapassados. Temos observados na leitura de textos que chegam para avaliação que a bibliografia traz como referências de autores importantes conceitualmente, mas não existe o cuidado de uma leitura crítica e atualização daqueles conhecimentos, já ultrapassados, ou que merecem uma analise crítica e/ou uma abordagem em perspectiva - seja porque preconizou e foi base de avanço - pois hoje a eles já se incorporaram novas reflexões.

Importante é atenção constante sobre os novos documentos oficiais, nacionais e internacionais, que trazem dados sempre mais atualizados, com perspectivas/abordagens atualizadas sobre os diferentes temas na área do envelhecimento.

A pesquisa e leitura devem ser constantes, mas sempre em perspectiva crítica, tendo como panorama a realidade do país no qual se vive e trabalha e suas características socioeconômicas e políticas. Este é um ponto fundamental: o que posso extrair de um ótimo estudo internacional para a realidade no qual estou inserida? Muitas vezes o que se preconiza como 'ideal' não condiz com a realidade vivida e, ponto fundamental: não generalizar porque não existem 'regras' para viver e longeviver.

O profissional - docente e pesquisador- deve ter sempre uma postura de 'buscador' e 'desbravador' e, importante, saber ler e compreender textos em língua estrangeira. Muitos dos documente oficiais internacionais 
são apresentadas também em português, mas nem sempre. A pesquisa constante em sites indexados e bem referenciados é igualmente uma pratica necessária visando à atualização. Ao não apresentar aqui referências bibliográficas não me eximo da responsabilidade, mas busco instigar não só a pesquisa, mas, e principalmente, a leitura crítica do material disponível. Ao longo do texto apresentei alguns autores e artigos, mais como pontos de referência na construção do meu caminho pessoal, ligado às raízes de uma formação humanística.

Por último, gostaria de alertar sobre a atenção necessária ante as perspectivas da longevidade avançada - $80+-$ e as necessidades que já se mostram no cotidiano, seja no caso dos ainda mais ativos, como dos mais comprometidos, lembrando que as demências senis já são, atualmente, consideradas questão de saúde publica.

Estes desafios são mundiais, mas devem ser postos na perspectiva do envelhecimento no Brasil, em momento de extrema instabilidade socioeconômica e com gritantes desigualdades em todos os níveis. Como profissionais e cidadãos devemos estar atentos às brechas para uma atuação responsável, cidadã e solidária - em meio ao turbilhão existem pessoas, de todas as idades e níveis sociais e de formação, e precisamos uns dos outros para superar e manter a dignidade que nos é própria. Quando nada parece possível, a atitude responsável de cada um e todos é a possibilidade de exercitar a cooperação solidária, que nos uniu, nos primórdios da nossa incipiente humanidade, e tornou possível a vida em grupo. Assim, devemos seguir, os desafios são outros, mas sabemos da força que temos para caminhar na busca de perspectivas mais promissoras para LongeViver. 